\title{
A photogrammetric approach for stability analysis of weathered rock slopes
}

Dong-Hyun Kim

Ivan Gratchev

Arumugam Balasubramaniam
Griffith School of Engineering, Griffith University, Australia

Griffith School of Engineering, Griffith University, Australia

Griffith School of Engineering, Griffith University, Australia

\begin{abstract}
:
The Geological Strength Index (GSI) system is dependent on the rock block volumes and the joint surface conditions. The weathering degree of rock slopes and their strength properties also depend on these characteristics. This study thus focuses on the use of the GSI system and the Hoek-Brown strength criterion to estimate the engineering parameters for weathered rock masses. Photogrammetric methods based on 3D surface models are used to obtain reliable data on the joint sets in rock slopes, instead of general site investigation using labor-intensive techniques. Photogrammetric surveys were conducted on weathered rock slopes in Gold Coast, Australia to obtain the joint spacing, orientation and roughness. The 3D models are then used to estimate the block sizes the joint roughness coefficients (JRC). The block volumes and JRC values were then used to estimate GSI values. Then parametric studies using the finite element method is conducted to investigate the stability of the slope using the GSI values.
\end{abstract}

Key words: photogrammetry, joint spacing, joint roughness coefficient, weathering, GSI, slope stability 


\section{Introduction}

This study seeks to estimate GSI values using photogrammetry to assess the stability of weathered rock slopes in the Tamborine mountain area, Gold Coast, Australia. These slopes have long experienced stability issues affecting the serviceability of the adjacent road. The GSI system is mainly used in the studies that follow a combination of the approaches of Hoek et al. (1997), Ehlen (1999), Palmström (2001), Cai et al. (2006) and Admassu (2012).

The geological strength index (GSI) system introduced by Hoek et al. (1997), is a powerful system of rock mass characterization which concentrates on the extent of blockiness and the surface condition of discontinuities. As the GSI values are estimated from visual observation of exposed outcrops, the use of GSI is subjective and requires much experience. Thus, as an effort to quantify GSI values for engineering purposes, Cai et al. (2006) proposed a quantitative method to estimate GSI using relationships between joint roughness number $\left(\mathrm{J}_{\mathrm{R}}\right)$, joint alteration number $\left(\mathrm{J}_{\mathrm{A}}\right)$ and block volume $\left(\mathrm{V}_{\mathrm{b}}\right)$ in three dimensional space.

The general way to obtain the joint properties is to observe rock slopes or boring logs. However, the traditional method may be time consuming and typically associated with risks during field works. To address this problem, the recent development of remote sensing techniques such as photogrammetry, has enabled the accurate estimation of the scale of rock block and orientation of the main joint sets. The technique also provides the 2D profiles and joint roughness coefficient (JRC) from 3D surface models using high resolution 3D digital images, for inaccessible rock slopes (Haneberg, 2007; Poropat, 2009; Guo et al., 2011; Kim et al., 2013).

During the weathering process, the rock mass becomes decomposed and the number of joint sets may be increased. Thus, the degree of weathering in blocky rock mass can be investigated by measuring the degree of jointing, which is related to the number of joint sets and joint spacing. However, this approach should be carefully considered due to the fact that the frequency of joints can also be caused by different geological processes such as tectonic disturbances (Marinos et al., 2005).

Block size and joint spacing are the main parameters to assess the degree of jointing in rock masses. Palmström (2001) presented correlations between block sizes and joint frequency $\left(\mathrm{J}_{\mathrm{v}}\right)$ and also RQD and $J_{v}$ using numerous measurement data. In terms of weathering, Ehlen (1999) showed the correlation between mean joint spacing and weathering grades. Similarly, Admassu (2012) suggested that joint spacing is an important factor contributing to slope failure. 
The slake durability and Schmidt rebound values can be used to estimate the strength of the weathered rock joints. Dick et al. (1994) noted that the durability of most rock is one of the most important parameters to the stability of the slopes. The slake durability test is to evaluate the influence of weathering on rocks by measuring the resistance to degradation and decomposition as simulated by being exposed to wetting and drying cycles. The study of Franklin and Chandra (1972) reported that slaking of rocks is an important consideration to evaluate the engineering behavior of rock mass and rock materials in geotechnical practices. Also, Schmidt hammer rebound values showed reliable results to classify weathering in the less weathered material (Arikan et al., 2007). Due to the reduction of strength of the weathered rock surface, rebound energy of Schmidt hammer can be absorbed. Sharma et al. (2011) showed a linear relation between the Schmidt rebound number and the impact strength index (ISI) and the slake durability index (SDI).

To investigate the behavior of rock masses for different weathering conditions, finite element analyses were also performed using the Hoek-Brown criterion based on the calculated GSI values.

\section{Estimation of the degree of jointing}

In principle, weathering causes lower values in the spacing of the joints and intact rock strength. As rock surfaces are exposed for a long time, the rock breaks into small pieces and the number of joint sets becomes visible. Hack (1997) investigated the influence of weathering for the parameters of intact rock strength and spacing of discontinuities. Similarly, Ehlen (1999) presented that joint spacing tends to become closer when weathering grades increase. The spacing of discontinuities will determine the dimensions of the rock blocks in the slope and the block volume is an extremely important parameter that is directly related to the rock mass classification systems.

The development of methods to estimate the block volumes has been described extensively in the literature. The correlation between the block volume $\left(\mathrm{V}_{\mathrm{b}}\right)$ and the volumetric joint count $\left(\mathrm{J}_{\mathrm{v}}\right)$ is proposed by Palmström (2001),

$$
V_{b}=\beta \times J_{v}^{-3}
$$

where, $\beta$ is the block shape factor.

The block shape factor can be estimated by eq.(2)

$$
\beta \approx 20+7 a 3 / a 1
$$

where $a 1$ and $a 3$ are the shortest and longest dimensions of the block. 
The volumetric joint count $\left(\mathrm{J}_{\mathrm{v}}\right)$ is a measure for the degree of jointing or the inter block size and it can be used as an input in the description of rock mass jointing (Palmström, 2001). The $\mathrm{J}_{\mathrm{v}}$ uses the term, joint spacing (S), which is the distance between an adjacent pair of discontinuities measured along a line on the rock surface. The $\mathrm{J}_{\mathrm{v}}$ count is defined as the number of joints intersecting a volume of $1 \mathrm{~m}^{3}$,

$$
\mathrm{JV}=1 / \mathrm{S}_{1}+1 / \mathrm{S}_{2}+1 / \mathrm{S}_{3}+\ldots 1 / \mathrm{S}_{\mathrm{n}}
$$

where, joint spacing (S) is $S_{1}, S_{2}$ and $S_{n}$ are the average spacing for the joint sets.

In three dimensional space, individual block volumes can also be estimated using joint spacing and their orientations. Assuming that the main joint sets were persistent, the block volume is calculated using Eq.(4) proposed by Cai et al. (2004),

$$
V_{b}=\frac{s_{1} s_{2} s_{3}}{\sin \gamma_{1} \sin \gamma_{2} \sin \gamma_{3}}
$$

where, $\mathrm{s}_{1}, \mathrm{~s}_{2}, \mathrm{~s}_{3}=$ spacing between discontinuity sets; $\gamma_{1}, \gamma_{2}, \gamma_{3}=$ angles between discontinuity sets.

\section{Quantification of GSI values}

The GSI is the geological index based on rock mass structures and joint surface conditions. Marinos et al. (2005) suggested that the GSI values in weathering condition can be estimated by shifting the values of the unweathered rock mass in the chart. However, this procedure tends to be subjective and requires long term experience. As the GSI values are estimated from visual observation of exposed outcrops, the GSI values for weathered rock masses can be assessed using the degree of jointing on the slope surfaces. Cai and Kaiser (2006) proposed a quantitative method to estimate GSI using the joint condition factor $\left(\mathrm{J}_{\mathrm{c}}\right)$ and rock block volume $\left(\mathrm{V}_{\mathrm{b}}\right)$ in three dimensional space. The GSI is defined from the following function,

$$
G S I=\frac{26.5+8.79 \ln J_{c}+0.9 \ln V_{b}}{1+0.0151 \ln J_{c}-0.0253 \ln V_{b}}
$$

where $V_{b}$ is the block volume and $J_{c}$ is a quantitative characterization factor to show joint condition. The joint condition factor, $\mathrm{J}_{\mathrm{c}}$ is defined as follows;

$$
J_{c}=\frac{J_{W} J_{S}}{J_{A}}
$$

where $\mathrm{J}_{\mathrm{W}}$ is a factor to describe large scale waviness of joints which is in meters from 1 to $10 \mathrm{~m}$ and $\mathrm{J}_{\mathrm{S}}$ is a term to describe small scale smoothness. $\mathrm{J}_{\mathrm{s}}$ is a parameter to describe joint surface roughness which is closely related to the joint roughness coefficient (JRC) defined by 
Barton et al. (as cited in Palmström, 2001). $\mathrm{J}_{\mathrm{A}}$ is the joint alteration factor which defines the filling of the joints.

As a main parameter, GSI values are applied in the Hoek-Brown failure criterion. The normal form of the Hoek-Brown failure criterion is Eq.(7),

$$
\sigma_{1}^{\prime}=\sigma_{3}^{\prime}+\sigma_{c i}\left(m_{b} \frac{\sigma_{3}^{\prime}}{\sigma_{c i}}+s\right)^{\alpha}
$$

where $\sigma^{\prime}{ }_{1}$ and $\sigma_{3}$ are the major and minor effective principal stresses and $\sigma_{\mathrm{ci}}$ is the uniaxial compressive strength of the rock. $\mathrm{m}_{\mathrm{b}}, \mathrm{s}$ and $\alpha$ are material constants for rock mass as follows;

$$
\begin{aligned}
& m_{b}=m_{i} \exp \left(\frac{G S I-100}{28-14 D}\right) \\
& s=\exp \left(\frac{G S I-100}{9-3 D}\right) \\
& \alpha=\frac{1}{2}+\frac{1}{6}\left(e^{-\frac{G S I}{15}}-e^{-\frac{20}{3}}\right)
\end{aligned}
$$

The deformation modulus in the GSI system can be estimated as follows;

$$
E=\left(1-\frac{D}{2}\right) \sqrt{\frac{\sigma_{c}}{100} 10^{\left(\frac{G S I-10}{40}\right)}} \mathrm{GPa} \quad\left(\text { for } \sigma_{\mathrm{c}}<100 \mathrm{MPa}\right)
$$

where $\mathrm{D}$ is the disturbance factor that depends on the degree of disturbance by blasting and stress relaxation (Hoek et al., 2002). For weathered rock masses, the constants $m_{i}$ and the unconfined strength of intact rock $\sigma_{\mathrm{ci}}$ in the Hoek-Brown criterion should be reduced in comparison with the unweathered rock masses (Marinos et al., 2005).

\section{Geological conditions of the study area}

\subsection{Geology}

The study areas are located on the eastern road near Tamborine mountain that is mainly composed of layered argillite and sandstone in Neranleigh-Fernvale Beds (Willmott, 2010; Gratchev et al., 2013; Shokouhi et al., 2013) (Fig. 1). In the study area, the rocks are heavily weathered, folded and steeply inclined. Argillite, which is hardened and slightly recrystallized shale, is fined-grained rock, bedding, and fractured in many exposures. The sandstone is mostly coarse-grained sediment of bright brown color. Recently, the slope experienced failures during heavy rainfall. It was observed from the site investigation that the rock beneath the failed area was deeply weathered and the bedding structure associated with other discontinuities was significant factor contributing to the failure.

\subsection{Strength properties of rock mass}

A series of point load tests and slake durability tests were performed on the both collected samples and core samples from the site (Fig. 2). The core samples from near sites were used 
as unweathered rocks which were not exposed to surface weathering. Fig. 3 shows the range of point load index (PLI) and the slake durability indices (SDI) of the rock samples. The samples were classified by the point load strength (Broch \& Franklin, 1972). A large number of weathered argillite samples exist in the 'high' strength category of PLI while the weathered sandstone samples are categorized as the 'medium' PLI.

The unconfined compressive strengths (UCS) were estimated from the results of the point load tests. The approximate conversion of UCS was performed using the conversion factor 24 as shown in Eq. (12) (Broch \& Franklin, 1972),

$$
\mathrm{UCS}=24 \times I_{S}(50)
$$

where, $I_{s}(50)$ is the point load strength index at a reference diameter of $50 \mathrm{~mm}$ for core samples. The laboratory tests also show that the samples with low values of unconfined compressive strength tend to have low values of slake durability index. The slake durability indices from the argillite samples range from $92.5 \%$ to $97 \%$ and the point load strength indices range from 1.53 to $3.31 \mathrm{MPa}$. The durability of argillite is classified as 'high' to 'extremely high' durability according to the slake durability index classification (Franklin \& Chandra, 1972). In contrast, a considerable difference in slake durability index $\left(\operatorname{Id}_{2}\right)$ of the sandstone was indicated between 'low to medium' $\left(\mathrm{Id}_{2}=50 \%\right)$ and 'very high' durability $\left(\mathrm{Id}_{2}=90.7 \%\right)$. As a result, the argillite of the study area has higher unconfined compressive strength and more durability than the sandstone.

During the site investigations, a total of 40 Schmidt hammer tests were performed on the discontinuities of the argillite and sandstone areas. Table 2 shows that the range of rebound values are between 11 and 49, which are classified as weathering grade III or IV for the both argillite and the sandstone areas (Arikan et al., 2007). The different weathering grades also indicate that the sandstone of the study area is less durable than the argillite.

\section{Assessment of joint properties using photogrammetry methods}

\subsection{Photogrammetry survey}

Photogrammetry survey was performed to produce 3D models of the slope surface model and determine the characteristics of discontinuities. A professional digital camera (Nikon D7000) and lens of $24 \mathrm{~mm}$ focal length lens was employed to capture high-quality digital images of the slope at two camera positions. The computer code "Sirovision" (CSIRO, 2005) was used to analyse the images and create 3D models of each slope site. Georeferencing was performed for the photo by determining the coordinates of the left camera position (using a GPS device), 
and measuring its bearing (azimuth) to the centre of slope (using a geological compass) (Sturzenegger, 2010).

\subsection{Degree of jointing}

The spacing and the orientations of joints were obtained from the 3D models. Mapping and tracing for the joint information was conducted manually on screen and provided the spacing and the length of the joint sets. The discontinuities data obtained from the 3D model were plotted on stereonets to determine the main joint sets. For the both argillite and sandstone, representative sampling areas, which are $3 \mathrm{~m} \times 3 \mathrm{~m}$ in dimension, were considered in this study (Fig. 4).

The block shapes in the sandstone area are more irregular than those of argillite (Fig. 4). Figure 5 shows the joint spacings of the main joint sets for the argillite and the sandstone. The overall joint spacing of the sandstone area is smaller than that of the argillite area. The measured distances and orientations of the discontinuity sets were used to assess the degree of jointing; block volumes, volumetric joint count and RQD. As a result, the block volumes and RQD values of argillite indicates higher values than those of sandstone as presented in Table 3. Even though the block sizes of both rock types can be formed based on different geologic processes such as tectonic movement, it is interesting that the sandstone area shows lower block volumes with lower weathering degrees (IV) than that of argillite (III) (See Table 2.).

\subsection{Estimation of GSI values}

The waviness of joint wall $\left(\mathrm{J}_{\mathrm{w}}\right)$ was estimated using undulations obtained by the roughness profiles extracted from the 3D models. The procedure can be applied with a $0.9 \mathrm{~m}$ long edge which is placed on the profiles as shown in Fig. 6. The concept of the measurement is the same as the procedure described by Piteau (1970).

In a small scale roughness, the joint smoothness factor $\left(\mathrm{J}_{\mathrm{s}}\right)$ can be associated with JRC values. In this study, $\mathrm{J}_{\mathrm{s}}$ values were estimated using the linear interpolation relationship between JRC values and $\mathrm{J}_{\mathrm{s}}$ (Eq. (13)). This relationship is based on the assumption that the range of $\mathrm{J}_{\mathrm{s}}$ (0.6 3.0) is directly proportional to the range of JRC (0 20).

$$
J_{S}=0.1125 \times J R C+0.75
$$

The JRC values were obtained using the Maerz et al. (1990) and Tse and Cruden (1979) approaches based on the surface profiles in $10 \mathrm{~cm}$ lengths which were extracted from the 3D models for the dip directions of the joints. 20 JRC values were calculated at different 
locations in each section. Figure 7 presents an example of roughness profiles extracted from the 3D model. JRC values were calculated using the code Sirovision with functions as follows,

$$
\begin{aligned}
& J R C=32.2+32.47 \log Z_{2} \quad \text { (Tse and Cruden, 1979) } \\
& J R C=411\left(R_{p}-1\right) \quad \text { (Maerz et al., 1990) }
\end{aligned}
$$

where, $Z_{2}$ is a roughness parameter using variances within asperity heights, and where $R_{p}$ is a roughness parameter which is related to the inclination angle (i) of the sawtooth surface of the roughness profile.

Figure 8 summarizes the obtained data, indicating a similar range of JRC values between both the argillite and sandstone areas from 7.4 to 10.3. Consequently, there is no significant difference between the mean values of $J_{s}$; however, in the large scale joint condition, the more undulating surfaces of the sandstone produced larger $\mathrm{J}_{\mathrm{C}}$ values than the argillite section, as presented in Table 4.

The GSI values were obtained from Eq. (5) (Cai \& Kaiser, 2006). The values were quantified by the estimated block volumes and joint condition factors $\left(\mathrm{J}_{\mathrm{c}}\right)$. The variation of GSI as a function of block volume $\left(\mathrm{V}_{\mathrm{b}}\right)$ and joint condition factor $\left(\mathrm{J}_{\mathrm{c}}\right)$ are plotted in Fig. 9. As shown in Fig. 9, the block volume is a less sensitive parameter to estimate GSI values than the joint condition factor. Figure 9(a) shows that even much larger blocks (100 times) with the same joint condition factors produce an increase only 10 GSI values. Therefore, joint condition factors can be more influential and thus should be carefully examined to quantify GSI values. For the study areas, the estimated GSI values and the Hoek-Brown strength parameters were given in Table 5. The numerical code 'RocData' (Rocscience) was used to estimate the HoekBrown strength parameters and the elastic modulus.

\section{Parametric study on the weathered rock slope}

Based on the estimated GSI values and the block sizes obtained from the 3D models, the parametric analyses were performed using a numerical code, Phase2 (Rocscience). This code is an elasto-plastic finite element program for calculating stresses and displacements of rock slopes, and also provides joint simulations. The failure mechanisms of the study area were simulated by two different criteria in numerical analyses. One was to investigate the influence of the block sizes on the behaviour of weathered slopes using the Mohr-Coulomb model, and the other was to examine the influence of GSI values on the failure behaviour for the same analysis section. Figure 10 demonstrates the numerical models for both cases.

Firstly, the numerical models using the Mohr-Coulomb criterion have one main joint set dipping $43^{\circ}$ along the slope and another cross-joint set generated perpendicular to the slope. 
In the parametric study, three different joint spaces $-10 \mathrm{~cm}, 20 \mathrm{~cm}$ and $40 \mathrm{~cm}$ for the main joint set and $20 \mathrm{~cm}, 40 \mathrm{~cm}$ and $80 \mathrm{~cm}$ for the cross-joint set - were considered in order to simulate different block sizes (Fig. 10(a)). For the joint parameters, the Barton-Bandis rock joint strength criterion was adopted and the peak friction angle which represents joint roughness condition, was estimated using the JRC values of Eq. (16) suggested by Barton et al. (1977),

$$
\phi=\phi_{\mathrm{r}}+\mathrm{JRC}_{\mathrm{n}} \log _{10}\left(\frac{\mathrm{JC} \mathrm{S}_{\mathrm{n}}}{\sigma_{\mathrm{n}}}\right)
$$

where, $\phi_{\mathrm{r}}=$ residual friction angle of joint; JCS $=$ joint wall compressive strength; $\sigma_{\mathrm{n}}=$ normal stress acting on the joint plane.

Secondly, the numerical models of the Hoek-Brown failure criterion were simulated for the same failure area. Based on three different GSI values, corresponding material constants described in Eq. $(8,9,10)$ were estimated by 'RocData'. The conditions for both numerical analyses are summarized in Table. 6.

Using the results of FEM analysis, slope failure mechanisms can be inferred from the assessment of total displacement. Figure 11 shows the total displacements from the parametric analyses of the slope models. Fig. 11(a) indicates that the variation in block size can affect the deformation of the slopes. As the block sizes increase, the deformation values diminish. However, increasing the block size does not significantly reduce the displacement of the slope. This is mainly because there are no other changes in the strength parameters except for block sizes. Based on the JRC values obtained from the 3D image, block size itself is not an influential factor for the study slope.

On the other hand, the results analysed from the Hoek-Brown criterion shows more sensitive variations of slope displacement. Figure 11(b) shows total displacement of the slope according to the variations of GSI values and material constants. The results of the analyses demonstrated that when the GSI value increased from 20 to 60, the maximum value of total displacement of the slope was considerably reduced. This means that the GSI values which are controlled by the block sizes and by joint conditions can affect strength characteristics in the Hoek-Brown criterion. Consequently, in numerical analyses, the block sizes are embedded in the GSI values, resulting in an effect on the behaviour of slopes with corresponding strength properties. Figure 12 shows the deformed mesh and the total displacement contours for each analysis.

\section{Conclusion}

The photogrammetry method was applied to investigate the stability of a weathered rock slope. Based on the obtained results, the following conclusions can be drawn: 
- Photogrammetry can provide reliable data on joint spacing and the block sizes of rock slopes based on the discontinuity sets in 3D models.

- In the study area, sandstone showed a higher weathering grade (IV) than argillite (III) and the block size of the slope can be an indicator of the weathering degree for the rock slopes.

- The 3D models can produce joint roughness coefficients (JRC) and these values were effectively used to estimate the joint smoothness factors $\left(\mathrm{J}_{\mathrm{s}}\right)$ that were essential in obtaining GSI values.

- In the quantification of GSI values using the function suggested by Cai \& Kaiser (2006), joint condition factor $\left(\mathrm{J}_{\mathrm{c}}\right)$ can be a more sensitive parameter than block sizes. In addition, block size itself was not a sensitive parameter in the results of the FEM analysis.

- Rock block sizes can be effectively considered using GSI systems, combined with photogrammetry 3D models, to estimate the corresponding strength parameters for the HoekBrown criterion for weathered rock slopes.

\section{Acknowledgement}

The authors wish to thank Mr. George Poropat from CSIRO for the valuable assistance.

\section{Reference}

Admassu Y, Shakoor A, Wells NA (2012) Evaluating selected factors affecting the depth of undercutting in rocks subject to differential weathering. Eng Geol 124: 1-11

Arikan F, Ulusay R, Aydin N (2007) Characterization of weathered acidic volcanic rocks and a weathering classification based on a rating system. Bull Eng Geol Env 66: 415-430

Barton N, Choubey V (1977) The Shear Strength of Rock Joints in Theory and Practice. Rock Mech 10: 1-54

Broch E, Franklin JA (1972) The point load strength test. Int J Rock Mech Min Sci 9: 669697

Cai M, Kaiser PK, Uno H, Tasaka Y, Minami M (2004) Estimation of rock mass deformation modulus and strength of jointed hard rock masses using the GSI system. Int J Rock Mech Min Sci 41: 3-19

Cai M, Kaiser PK (2006) Visualization of rock mass classification systems. Geotech Geol Eng 24: 1089-1102

CSIRO (2005) Field procedures for photogrammetric pit mapping. CSIRO Exploration \& Mining 
Dick JC, Shakoor A, Wells N (1994) A geological approach toward developing a mudrockdurability classification system. Can Geotech J 31: 17-27

Ehlen J (1999) Fracture characteristics in weathered granites. Geomorphology 31: 29-45

Franklin JA, Chandra A (1972) The slake durability test. Int J Rock Mech Min Sci 9: 325-341

Gratchev I, Shokouhi A, Kim D, Stead D, Wolter A (2013) Assessment of rock slope stability using remote sensing technique in the Gold Coast area, Australia. In: Proceedings of the $18^{\text {th }}$ Southeast Asian Geotechnical \& Inaugural AGSSEA Conference, pp 729-734

Guo H, Karekal S, Poropat G, Soole P, Lambert C (2011) Pit wall strength estimation with 3D imaging. CSIRO, ACARP

Haneberg WC (2007) Directional roughness profiles from three-dimensional photogrammetric or laser scanner point clouds. In: Proceedings of the $1^{\text {st }}$ Canada-U.S. Rock Mechanics symposium, Vancouver, pp 101-106

Hack R, Price D (1997) Quantification of weathering. In: Proceedings of Engineering geology and the envirionment, Athens, Balkema, Rotterdam, pp 145-150

Hoek E, Brown ET (1997) Practical estimates of rock mass strength. Int J Rock Mech Min Sci 34(8): 1165-1186

Hoek E, Carranza-Torres C, Corkum B (2002) Hoek-Brown failure criterion-2002 edition. In: Proceedings of NARMS-TAC conference, Toronto, pp 267-273

Kim DH, Gratchev I, Balasubramaniam AS (2013) Determination of joint roughness coefficient (JRC) for slope stability analysis : a case study from the Gold Coast area, Australia. Landslides, doi: 10.1007/s10346-013-0410-8

Maerz NH, Franklin JA, Bennett CP (1990) Joint roughness measurement using shadow profilometry. Int J Rock Mech Min Sci 27: 329-343

Marinos V, Marinos P, Hoek E (2005) The geological strength index: applications and limitations. Bull Eng Geol Env 64: 55-65

Poropat GV (2009) Measurement of surface roughness of rock discontinuities. In: Proceedings of the $3^{\text {rd }}$ CANUS Rock Mechanics Symposium, Toronto, Canada, paper 3976

Palmström A (2001) In-Situ characterization of rocks. A.A.Balkema Publishers, Lise/Abingdon/Exton(PA)/ Tokio

Piteau DR (1970) Geological factors significant to the stability of slopes cut in rock. In: Proceedings of the on planning open pit mines, Johannesburg, South Africa, pp 33-53 
Sharma PK, Khandelwal M, Singh TN (2011) A correlation between Schmidt hammer rebound numbers with impact strength index, slake durability index and P-wave velocity. Int J Ear Sci (Geologische Rundschau) 100: 189-195

Shokouhi A, Gratchev I, Kim D (2013) Rock slope stability problems in Gold Coast area, Australia. Int J GEOMATE 4(1): 501-504

Sturzenegger M (2010) Multi-scale characterization of rock mass discontinuities and rock slope geometry using terrestrial remote sensing techniques. PhD thesis, Simon Fraser University

Tse R, Cruden DM (1979) Estimating joint roughness coefficients. Int J Rock Mech Min Sci 16: $303-307$

Willmott WF (2010) Rocks and landscape of the Gold Coast hinterland. Geological society of Australia, Queensland division 


\section{Lists of figures}

Fig. 1 Geological conditions of study area, argillite (a) and sandstone (b)

Fig. 2 Collected rock samples

Fig. 3 Unconfined compressive strength (UCS) and slake durability index $\left(\mathrm{Id}_{2}\right)$ according to point strength classification.

Fig. 4 Main joint sets of the selected areas based on the 3D model (Sirovision)

Fig. 5 Variations in the spacing of joints

Fig. 6 Estimation of undulation using 3D models

Fig. 7 JRC values estimated from 3D models, 3D image (a) JRC values and roughness profiles (b)

Fig. 8 Distribution of JRC data obtained from 3D image

Fig. 9 GSI variation with $\mathrm{V}_{\mathrm{b}}$ (a) and $\mathrm{J}_{\mathrm{c}}$ (b) based on Eq. (5)

Fig. 10 Numerical models for the parametric study using Phase2, Mohr-Coulomb model (a), Hoek-Brown model (b)

Fig. 11 Variation of maximum displacement with block volumes (a) and with GSI values (b)

Fig. 12 Contours of total displacement (sandstone), Mohr-Coulomb model (a c), HoekBrown model (d) 